\title{
Correction to: Moving Beyond Global Warming Potentials to Quantify the Climatic Role of Ecosystems
}

\author{
Scott C. Neubauer ${ }^{1 *}$ and J. Patrick Megonigal ${ }^{2}$
}

${ }^{1}$ Department of Biology, Virginia Commonwealth University, 1000 West Cary Street, Richmond, Virginia 23284, USA; ${ }^{2}$ Smithsonian Environmental Research Center, P.O. Box 28, Edgewater, Maryland 21037, USA

\section{CoRrection to: Ecosystems (2015) 18: 1000-1013 HTTPS:/DOI.ORG/10.1007/s10021-015-9879-4}

In our 2015 paper, we dropped the $e^{(-d t / \tau)}$ term from Equations (1) and (2) when an ecosystem removed $\mathrm{CH}_{4}$ or $\mathrm{N}_{2} \mathrm{O}$ from the atmosphere, reasoning that greenhouse gases that are not in the atmosphere cannot undergo atmospheric oxidation or photolysis. The flaw in this logic is that the uptake of greenhouse gases by an ecosystem has the effect of reducing the pool of bulk atmospheric greenhouse gases and, consequently, lowering the decay rate of those gases. This violates our implicit assumption that the pool of bulk atmospheric greenhouse gases is in steady state and not affected by the ecosystem. To account for this, the $e^{(-d t / \tau)}$ term needs to remain in the model, with the result that the exact same equation is used when an ecosystem exhibits sustained greenhouse gas emissions or uptake. We thank Paavo Ojanen for bringing this error to our attention.

Published online 24 July 2019

The original article can be found online at https://doi.org/10.1007/s100 21-015-9879-4.

*Corresponding author; e-mail: sneubauer@vcu.edu
With the corrected model, the instantaneous radiative forcing due to sustained ecosystem emissions is equal in magnitude-but opposite in sign - to that caused by sustained ecosystem uptake (compare Figures 2B and 2C). Thus, the values for the sustained-flux global warming potential (SGWP) and sustained-flux global cooling potential (SGCP) should be exactly the same (Table 1); our initially reported SGCPs were too high.

Correcting this error does not change our conclusion that the global warming potential is the wrong metric to use when evaluating the climatic effects of ecosystems. However, it does mean that we overstated the magnitude of cooling that occurs when an ecosystem removes greenhouse gases from the atmosphere.

Additionally, in Equation (3), the $M_{\mathrm{CH}_{4} \text {-ox }}$ term should have been defined as $\left[M_{\mathrm{CH}_{4}-\mathrm{C},(\mathrm{t}-1)} \times\left(1-e^{\left(-d t / \tau_{\mathrm{CH}_{4}}\right)}\right)\right]$. This typographical error does not affect any of the results presented in the paper. We thank Pierre Taillardat for helping us locate this error. 


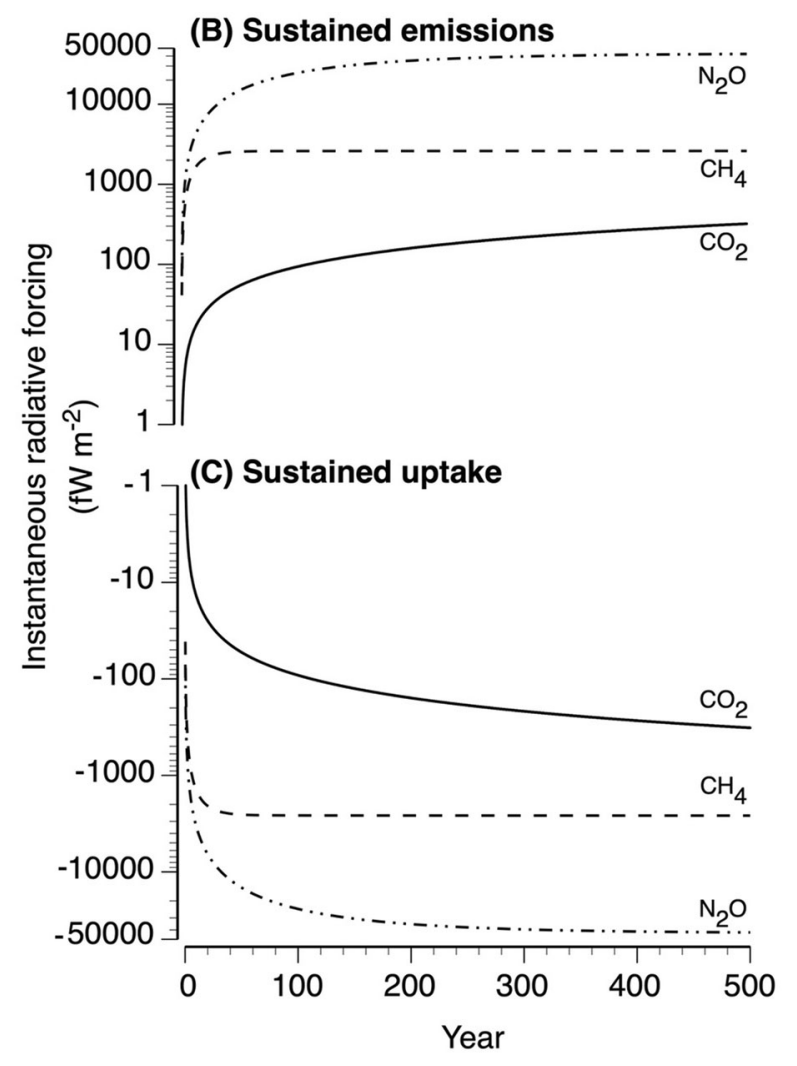

Corrected Figure 2. Radiative forcing due to sustained emissions (B) or sustained uptake (C) of $\mathrm{CO}_{2}, \mathrm{CH}_{4}$, and $\mathrm{N}_{2} \mathrm{O}$ throughout the model period. All fluxes were $1 \mathrm{~kg} \mathrm{~m}^{-2} \mathrm{y}^{-1}$. In all panels, the " $\mathrm{CH}_{4}$ " curves include any radiative forcing by $\mathrm{CO}_{2}$ that was produced from the oxidation of atmospheric $\mathrm{CH}_{4}$. Note the logarithmic scale on the $\mathrm{y}$-axes. $\mathrm{fW}=10^{-15} \mathrm{~W}$. Panel $\mathrm{B}$ is the same as in the original article. Panel $\mathrm{C}$ is based on the corrected equations for sustained greenhouse gas uptake.
Corrected Table 1. Global Warming Potentials (GWPs), Sustained-Flux Global Warming Potentials (SGWPs), and Sustained-Flux Global Cooling Potentials (SGCPs).

\begin{tabular}{|c|c|c|c|c|}
\hline \multirow[t]{2}{*}{ Gas } & \multicolumn{2}{|l|}{ (Years) } & \multirow{2}{*}{$\begin{array}{l}\text { (Emissions) } \\
\text { SGWP }\end{array}$} & \multirow{2}{*}{$\begin{array}{l}\text { (Uptake) } \\
\text { SGCP }\end{array}$} \\
\hline & Time frame & GWP & & \\
\hline $\mathrm{CO}_{2}$ & Any & 1 & 1 & 1 \\
\hline \multirow[t]{3}{*}{$\mathrm{CH}_{4}$} & 20 & 87 & 96 & 96 \\
\hline & 100 & 32 & 45 & 45 \\
\hline & 500 & 11 & 14 & 14 \\
\hline \multirow[t]{3}{*}{$\mathrm{N}_{2} \mathrm{O}$} & 20 & 260 & 250 & 250 \\
\hline & 100 & 263 & 270 & 270 \\
\hline & 500 & 132 & 181 & 181 \\
\hline
\end{tabular}

Table 1 legend: The GWP values were calculated from a single gas pulse that was allowed to decay for 20,100, or 500 years (Figure 2A). The SGWP and SGCP values were calculated assuming a sustained gas flux rate (emission or uptake, respectively) of $1 \mathrm{~kg} \mathrm{~m}^{-2} y^{-1}$ over the relevant time period (Figure $2 B$ and $2 C$ ). The SGWP indicates how many kilograms of $\mathrm{CO}_{2}$ must be sequestered to offset the emission of $1 \mathrm{~kg}$ of $\mathrm{CH}_{4}$ or $\mathrm{N}_{2} \mathrm{O}$; also see Figure 3. The SGCP indicates how many kilograms of $\mathrm{CO}_{2}$ must be sequestered to have the same cooling effect as the uptake of $1 \mathrm{~kg}$ of $\mathrm{CH}_{4}$ or $\mathrm{N}_{2} \mathrm{O}$. 